(C) [2009] IEEE. Reprinted, with permission, from Guo Youguang; Zhu Jianguo; Dorrell David 2009, 'Design and Analysis of a Claw pole Permanent Magnet Motor with Molded Soft Magnetic Composite Core', Design and Analysis of a Claw pole Permanent Magnet Motor with Molded Soft Magnetic Composite Core, vol. 45, no. 10 , pp. 4582-4585. This material is posted here with permission of the IEEE. Such permission of the IEEE does not in any way imply IEEE endorsement of any of the University of Technology, Sydney's products or services. Internal or personal use of this material is permitted. However, permission to reprint/republish this material for advertising or promotional purposes or for creating new collective works for resale or redistribution must be obtained from the IEEE by writing to pubspermissions@ieee.org. By choosing to view this document, you agree to all provisions of the copyright laws protecting it. 


\title{
Design and Analysis of a Claw Pole Permanent Magnet Motor with Molded Soft Magnetic Composite Core
}

\author{
Youguang Guo, Senior Member, IEEE, Jianguo Zhu, Senior Member, IEEE, and D. G. Dorrell, Senior Member, \\ IEEE
}

School of Electrical, Mechanical and Electronic Systems, University of Technology Sydney, NSW 2007, Australia

\begin{abstract}
SMC (Soft magnetic composite) materials and SMC electromagnetic devices have undergone substantial development in the past decade. Much work has been conducted on designing and prototyping various types of electrical machine. However, the iron cores were often made by cutting existing SMC preforms which were formed by compacting SMC powder in simple cylinder or bar shape molds, and the magnetic properties of the cores may deteriorate significantly during the cutting process. To investigate "industry production ready" products, this paper presents the design and analysis of a claw pole permanent magnet (PM) motor with a molded SMC core of low mass density to replace the existing induction motor in a dishwasher pump. The magnetic properties of the molded SMC core are measured and utilized in the motor design and analysis. Finite element analysis of magnetic field is carried out to accurately determine key motor parameters, and an improved phase variable model is applied to predict the motor performance. Both parameter computation and performance prediction are validated by the experimental results on the prototype.
\end{abstract}

Index Terms - Soft magnetic composite (SMC); molded SMC core; claw pole permanent magnet motor; finite element analysis of magnetic field; improved phase variable model.

\section{INTRODUCTION}

$\mathrm{B}$ ECAUSE OF the many unique properties such as magnetic isotropy, very low eddy current, great design flexibility and great potential for low cost mass production, soft magnetic composite (SMC) materials and their application in electromagnetic devices have undergone significant development in the past decade [1]. A large amount of research has been conducted by various researchers on designing and prototyping various types of electrical machines [2]-[6] using SMC material. Notable examples include claw pole and transverse flux motors featuring complex structures and 3-D flux paths [7], where it is difficult to use laminated steels so that SMC seems to be an ideal substitute.

However, most of the SMC motor prototypes investigated used iron cores cut from existing preforms which were previously compacted with high pressure in a simple shape mold such as cylinder and bar. The wire-cutting technique may be convenient and cost-effective for fabricating laboratory prototypes but would not be appropriate for commercial productions due to the large cost of a single processing. Also, the cutting process may significantly reduce the magnetic and mechanical properties of the SMC core.

In commercial production, the manufacturing cost of the SMC motor can be dramatically reduced if a high-productivity low-pressure press is used in the molding. On the other hand, the magnetic properties of the SMC core and hence the motor performance depends greatly on the mass density of the core. To investigate "industry production ready" products, the authors have recently developed techniques for the design and prototyping of permanent magnet (PM) motors with low density molded SMC cores. As an example, this paper presents the development of a claw pole PM SMC motor for replacing an existing single phase induction motor in a dish washer pump. A mold for pressing SMC claw pole disk was designed and made. SMC cores were compacted with different pressures and the corresponding magnetic properties were measured and applied in the design and analysis of the motor. The SMC motor is designed within the envelop of the original induction motor and produces the same output.

To accurately determine the magnetic field distribution and key parameters of the claw pole motor, 3-D magnetic field finite element analysis (FEA) was carried. To effectively predict the dynamic and steady-state performance, an improved phase variable model was adopted. The motor prototype has been fabricated and tested, validating the parameter computation and performance analysis.

\section{SMC CORE AND PROTOTYPE MOTOR}

Fig. 1 shows the SMC claw pole disk compacted in a mold with a single step press (no further machining required), and Fig. 2 the assembled 3 phase stator core. Each phase consists of two disks with a concentrated global coil in between, and the stator is formed by stacking three phases axially with a circumferential shift of $120^{\circ}$ electrical from each other. The major structural parameters include: stator inner diameter of $43 \mathrm{~mm}$, stator outer diameter of $67 \mathrm{~mm}$, effective axial length of $55 \mathrm{~mm}$, and air-gap of $1 \mathrm{~mm}$. $12 \mathrm{NdFeB}$ magnets with dimensions of $55 \times 6.7 \times 3 \mathrm{~mm}^{3}$ are mounted on the surface of a mild steel rotor. The motor is designed to operate at 3000 rpm, delivering a power of $60 \mathrm{~W}$.

The stator core disks were compacted in a mold with a pressure of 20 ton force (about $179 \mathrm{MPa}$ ) or 100 ton force (895 MPa), which is slightly higher than $800 \mathrm{MPa}$, the nominal pressure for the SMC material [1]. The average mass densities are $5.8 \mathrm{~g} / \mathrm{cm}^{3}$ and $7.2 \mathrm{~g} / \mathrm{cm}^{3}$, respectively. As shown in Fig. 3, the measured B-H curve of the $5.8 \mathrm{~g} / \mathrm{cm}^{3}$ core is much lower than that of the $7.2 \mathrm{~g} / \mathrm{cm}^{3}$ core. On the other hand, the low density cores can be compacted by small pressure, which yields much higher productivity than large ones. This 
can be attractive for industry applications. In this paper, the molded SMC core of $5.8 \mathrm{~g} / \mathrm{cm}^{3}$ is employed.

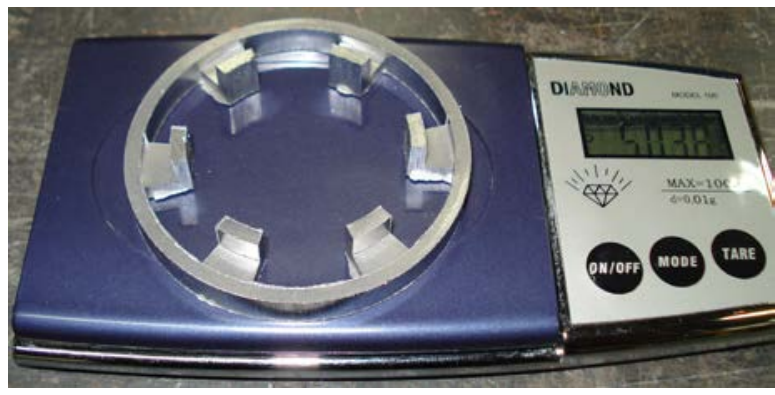

Fig. 1. Molded SMC claw pole disk

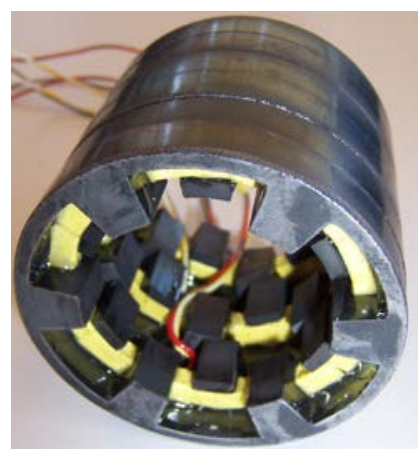

Fig. 2. Molded stator of a 3-phase claw pole motor

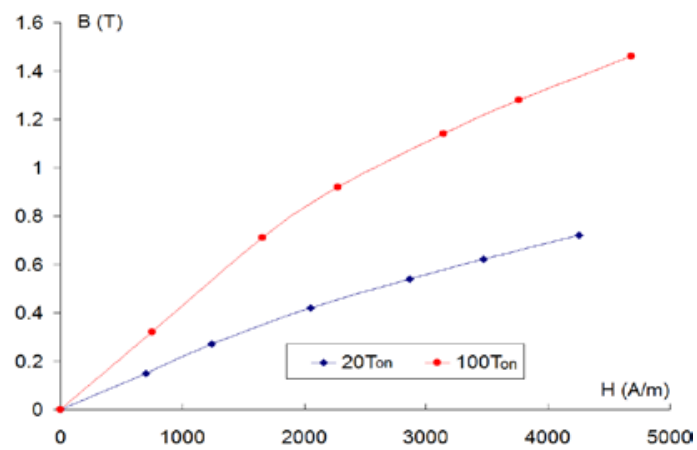

Fig. 3. Measured B-H curves of compacted SMC cores

\section{Finite ELEMENT ANALYSIS OF MAGNETIC FIELD AND COMPUTATION OF MOTOR PARAMETERS}

Due to the complex structure and 3-D magnetic flux path of the claw pole motor, numerical analysis of magnetic field by for example finite element method is necessary to accurately determine the magnetic field distribution and major parameters. By ignoring the magnetic coupling between stacks and considering the structural symmetry, only a pole region of one stack is needed for the field analysis. On the two radial boundary surfaces, the scalar magnetic potentials should obey the following half-periodical boundary conditions:

$$
\varphi_{m}(r, \theta, z)=-\varphi_{m}(r, \theta+\Delta \theta,-z)
$$

where $\Delta \theta=30^{\circ}$ is the angle of one pole pitch, and the origin is located in the centre of the stack.

Fig. 4 illustrates the magnetic flux density vector plot at no-load at $\theta=0^{\circ}$, where the claw poles face rotor magnets. It can be seen that the magnetic flux flows along 3-D path and a substantial flux leakage exists. From the no-load magnetic field distribution, a number of major motor parameters can be determined. For example, Fig. 5 plots the computed flux linking a phase winding, produced by the rotor PMs, against rotor position. The back electromotive force (EMF) can be easily obtained by differentiating the flux waveform with respect to rotor position or time. The cogging torque curve can also be obtained by using the virtual work method or the Maxwell stress tensor method using the field distribution.
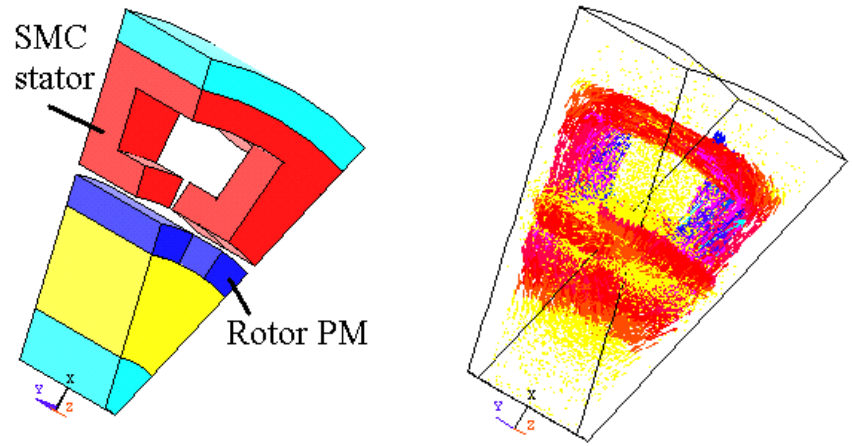

Fig. 4. Flux density vector plot at no-load

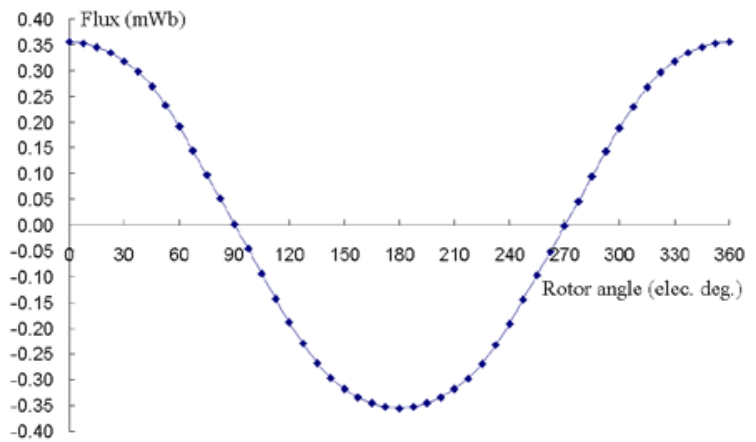

Fig. 5. Per-turn flux of a phase winding produced by rotor PMs

Unlike conventional machines, claw pole SMC motors usually have largely variable inductance and core loss when the rotor rotates. These variations can be easily obtained by using the time-stepping finite element analysis (FEA). Fig. 6 plots the inductance of a phase winding by using a modified incremental energy method [8].

Fig. 7 shows the transient core loss which was obtained using the following three-term formulation [9]:

$$
P_{f e}=\left\{\sum_{j=x}^{z}\left|H_{j} \frac{d B_{j}}{d t}\right|^{\frac{2}{\beta}}\right\}^{\frac{\beta}{2}}+\frac{k_{c}}{2 \pi^{2}} \sum_{j=x}^{z}\left(\frac{d B_{j}}{d t}\right)^{2}+\frac{k_{e}}{C_{e}}\left\{\sum_{j=x}^{z}\left(\frac{d B_{j}}{d t}\right)^{2}\right\}^{\frac{3}{4}}
$$

where the coefficients $\beta, k_{c}, k_{e}$ and $C_{e}$ are obtained by curve fitting the results from the measurements on the SMC sample. The calculation uses each element (for which the flux density and field strength are obtained) in the time-stepping FEA solutions. 


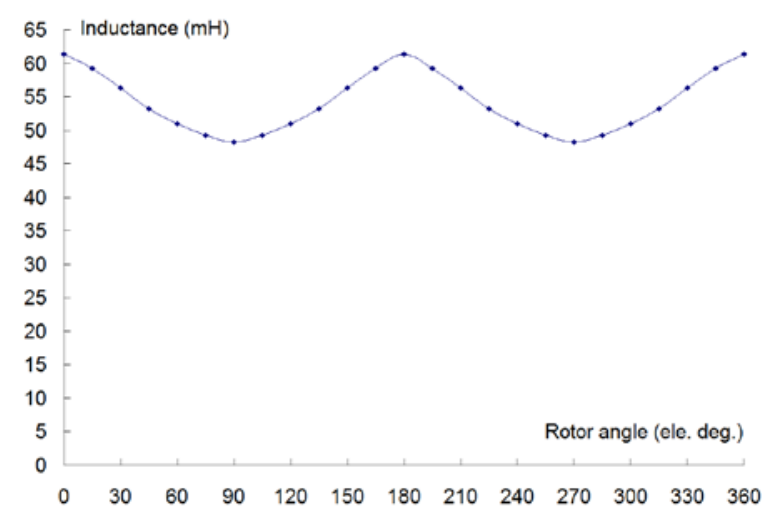

Fig. 6. Incremental inductance of a phase winding

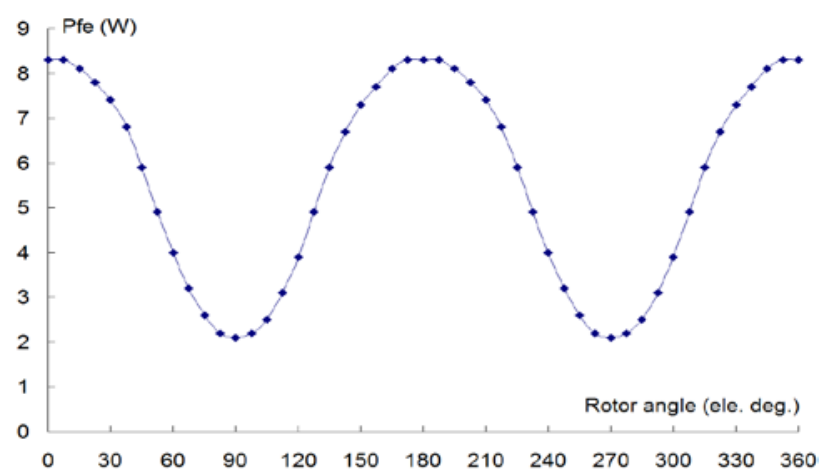

Fig. 7. Transient core loss

\section{IMPROVED Phase VARIABLE MODEL AND MOTOR PERFORMANCE PREDICTION}

An improved phase variable model [10] is applied to analyze the performance of the motor driven by a sensorless brushless DC (BLDC) controller [11], which can produce a reasonably sinusoidal phase voltage waveform to match that of the motor back-EMF. The phase variable model consists of a few electrical and mechanical equations as the following, where $L_{j k}$ is the apparent inductance which is independent of the stator currents, and $L_{j k}^{\prime}$ the incremental inductance. All other parameters are used as their conventional meaning.

$$
\begin{gathered}
v_{j}=r_{j} i_{j}+\frac{d \lambda_{j}}{d t}+e_{j} \lambda_{j}=\sum_{k=a}^{c} L_{j k} i_{k}, j=a, b, c \\
\frac{d \lambda_{j}}{d t}=\sum_{k=a}^{c} \frac{\partial \lambda_{j}}{\partial i_{k}} \frac{d i_{k}}{d t}+\frac{\partial \lambda_{j}}{\partial \theta_{r}} \frac{d \theta_{r}}{d t}=\sum_{k=a}^{c}\left(L_{j k}^{\prime} \frac{d i_{k}}{d t}+\frac{d L_{j k}}{d \theta_{r}} i_{k} \omega_{r}\right) \\
T_{e m}=\left(\sum_{j=a}^{c} e_{j} i_{j}\right) / \omega_{r}+T_{c o g} \\
J \frac{d \omega_{r}}{d t}=T_{e m}-\frac{P_{f e}}{\omega_{r}}-T_{L}-\delta \omega_{r}, \frac{d \theta_{r}}{d t}=\omega_{r} \\
r_{j}=r_{k}, L_{j k}=L_{k j}, \sum_{j=a}^{c} i_{j}=0,(j, k=a, b, c)
\end{gathered}
$$

In BLDC operation, one of the 3 phase windings is not excited and the voltage of the phase is not measurable, so the equations based model cannot be applied directly and an alternative model, consisting of several circuit components, has to be used [12]. To estimate the voltage (potential) of the neutral point and then the voltage of the non-excited phase winding, the following equation is used in this paper.

$$
U_{a}=U_{N}+\sum_{j=a}^{c} L_{j a}^{\prime} \frac{d i_{a}}{d t}+e_{a}+\sum_{k=b}^{c}\left(L_{a k}^{\prime} \frac{d i_{k}}{d t}+\frac{d L_{a k}}{d \theta_{r}} i_{k} \omega_{r}\right)
$$

The improved phase variable model can simulate the motor performance must faster than the FEA but with the same level of accuracy. The rotor position dependence of key motor parameters, i.e., the waveforms of the winding flux, back-EMF, winding inductance, core loss and cogging torque against rotor angle or time are all obtained in advance using a series of time-stepping magnetic field FEA solutions and stored in lookup table for retrieval for performance simulation.

Using the above equations, a model was developed in Simulink, which can simulate both the steady-state and dynamic performances of the motor. For example, Fig. 8(a) illustrates the simulated speed curve from start-up, showing that the motor can accelerate smoothly to the rated speed of $3000 \mathrm{rpm}$ with the rated torque of $0.2 \mathrm{Nm}$, while Fig. 8(b) shows the simulated steady-state electromagnetic torque ripple, which is caused by cogging torque, transient core-loss torque and phase-current switching. Fig. 9 plots the simulated applied voltage and current of one phase.

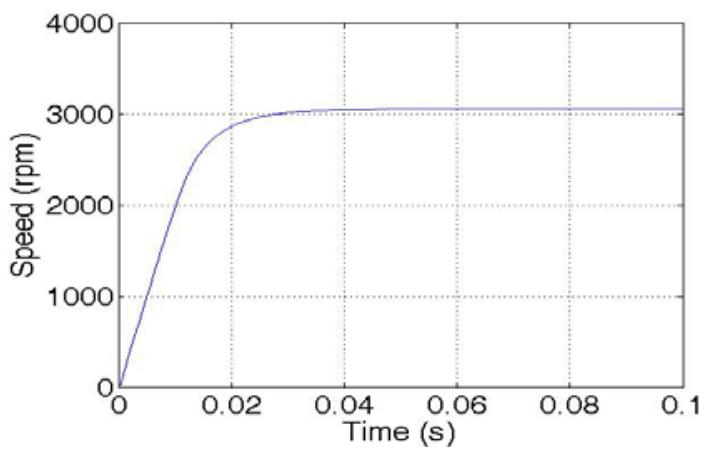

(a)

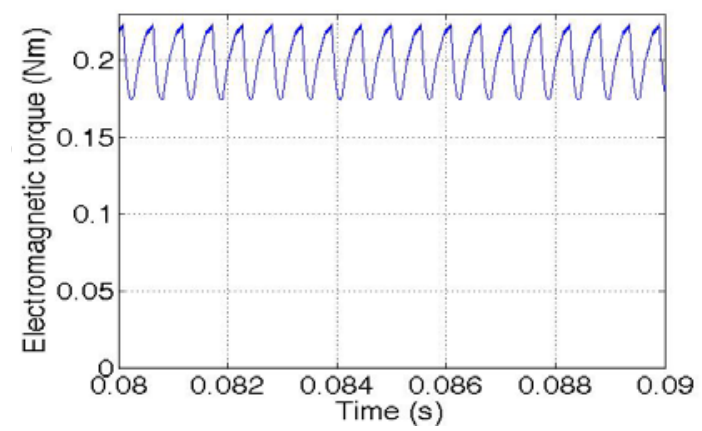

(b)

Fig. 8. Predicted motor performance: (a) speed curve during start-up; (b) steady-state electromagnetic torque curve 

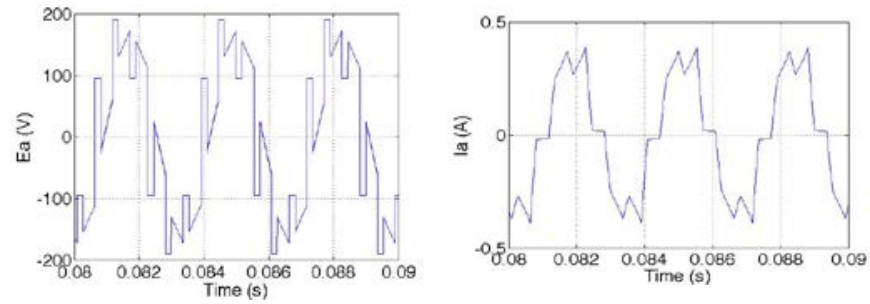

Fig. 9. Simulated phase voltage and current

\section{EXPERIMENTAL VALIDATION}

The motor parameter computation has been verified by the measurement. For example, the back-EMF waveform (open circuit voltage) was recorded on a CRO when the rotor was rotated. It was approximately sinusoidal in waveform and the peak-to-peak EMF was $46.5 \mathrm{~V}$ at $39.7 \mathrm{~Hz}$, therefore it can be deduced that the per-turn flux of stator winding produced by the rotor PMs is $0.364 \mathrm{mWb}$, which is very close to the calculation. With the voltage-current method, the equivalent phase winding inductance was measured as $50.9 \mathrm{mH}$, which is close to the average value of $54.0 \mathrm{mH}$ in Fig. 6. The mutual inductance is measured as only about $5 \%$ the self inductance.

Fig. 10 illustrates the experimental setup for measuring the motor performance. The SMC motor prototype is on the right and a dynamo load cell is on the left. A torque transducer is mounted between the motor and the load for measuring the shaft torque and speed. Fig. 11 plots the measured mechanical characteristics, i.e. the motor speed against applied DC link voltage of the inverter with certain load. The motor can successfully deliver a torque of $0.2 \mathrm{Nm}$ at $3000 \mathrm{rpm}$ while the inverter is supplied with a DC link voltage of about $290 \mathrm{~V}$.

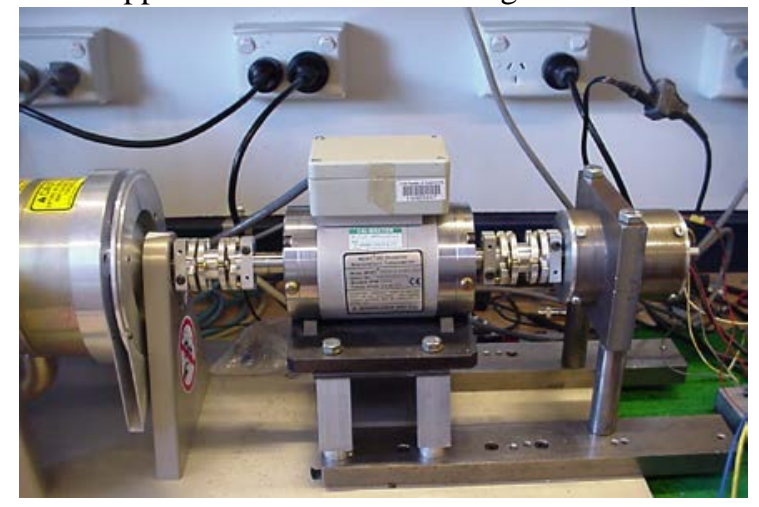

Fig. 10. Experimental setup

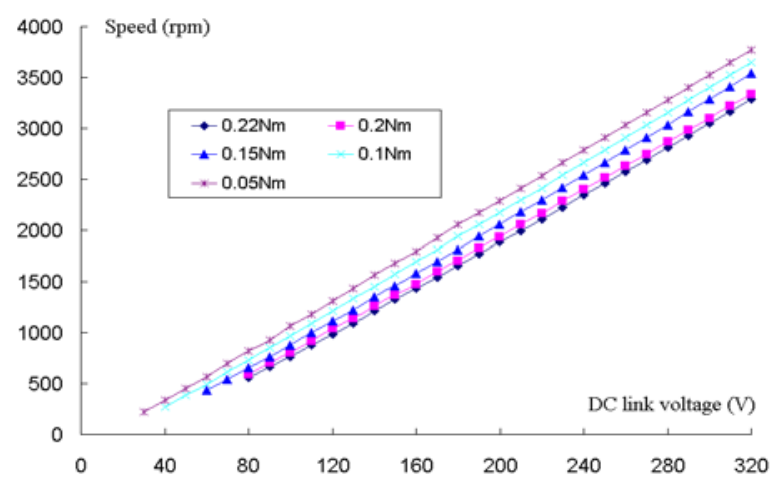

Fig. 11. Speed vs. DC link voltage with constant torque

\section{CONCLUSION AND DISCUSSION}

This paper presents the design and analysis of a claw pole PM motor with molded SMC core. The core was compacted at a low pressure of $179 \mathrm{MPa}$ and hence has a low mass density of $5.8 \mathrm{~g} / \mathrm{cm}^{3}$, which has great benefit for molding. If the motor were made with a high density SMC core of $7.2 \mathrm{~g} / \mathrm{cm}^{3}$, FEA results show that the back-EMF would increase by $18 \%$. In other words, the lower density SMC motor should have a larger volume core for the same output; this is not a difficulty for our design for replacing an existing induction motor.

Furthermore, the inductance of high density SMC is calculated as $20 \%$ lower. This means that the low density SMC motor must operate with a higher $\mathrm{V}$-A rating inverter. For this $60 \mathrm{~W}$ motor application, we used 320 VDC as in Fig. 11.

\section{ACKNOWLEDGMENT}

This work was supported in part by the Australian Research Council under Linkage Project Grant No. LP0454306.

\section{REFERENCES}

[1] "The latest development in soft magnetic composite technology," SMC Update, Reports of Höganäs AB, Sweden, 1997-2008. Available at http://www.hoganas.com/.

[2] A. G. Jack, "Experience with the use of soft magnetic composites in electrical machines," in Proc. Int. Conf. on Electrical Machines, Istanbul, Turkey, 1998, pp. 1441-1448.

[3] J. Cros, P. Viarouge, Y. Chalifour, and J. Figueroa, "A new structure of universal motor using soft magnetic composites," IEEE Trans. on Industry Applications, vol. 40, pp. 550-557, 2004.

[4] M. A. Khan, Y. Chen, and P. Pillay, "Application of soft magnetic composites to PM wind generator design," in Proc. IEEE PES general Meeting, 2006.

[5] G. Gvetkovski and L. Petkovska, "Performance improvement of PM synchronous motor by using soft magnetic composite material," IEEE Trans. Magn., vol. 44, no. 11, pp. 3812-3815, Nov. 2008.

[6] D. H. Kim, J. K. Sykulski, and D. A. Lowther, "The implications of the use of composite materials in electromagnetic device topology and shape optimization," IEEE Trans. Magn., vol. 45, no. 3, pp. 1154-1157, Mar. 2008.

[7] Y. G. Guo, J. G. Zhu, P. A. Watterson, and W. Wu, "Comparative study of 3-D flux electrical machines with soft magnetic composite core," IEEE Trans. Ind. Applications, vol. 39, no. 6, 1696-1703, Nov. 2003.

[8] Y. G. Guo, J. G. Zhu, and H. Y. Lu, "Accurate determination of parameters of a claw pole motor with SMC stator core by finite element magnetic field analysis," IEE Proceedings - Electric Power Application, vol. 153, no. 4, pp. 568-574, July 2006.

[9] D. Lin, P. Zhou, W. N. Fu, Z. Badics, and Z. J. Cendes, "A dynamic core loss model for soft ferromagnetic and power ferrite materials in transient finite element analysis," IEEE Trans. Magn., vol. 40, no. 2, pp. 1318-1321, Mar. 2004.

[10] J. X. Chen, Y. G. Guo, J. G. Zhu, and J. X. Jin, "Performance analysis of a surface mounted permanent magnet brushless DC motor using an improved phase variable model," in Proc. 42 ${ }^{\text {nd }}$ IEEE Industry Applications Society Annual Conf., Sept. 2007, pp. 2169-2174.

[11] W. M. Holliday, A Sensorless Brushless DC Controller, Internal Document of University of Technology Sydney.

[12] O. A. Mohammed, S. Liu, and Z. Liu, "A phase variable model of brushless DC motors based on finite element analysis and its coupling with external circuits," IEEE Trans. Magn., vol. 41, no. 5, pp. 15761579, May 2005.

Manuscript received March 6, 2009, revised April 9, 2009. Corresponding author: Youguang Guo (e-mail: youguang@eng.uts.edu.au). 